\title{
Clinical Characteristics of the Respiratory Subtype in Panic Disorder Patients
}

\author{
Hye-Min Song ${ }^{1}$, Ji-Hae $\mathrm{Kim}^{2}$, Jung-Yoon $\mathrm{Heo}^{3}$, and Bum-Hee $\mathrm{Yu}^{2} \bowtie$ \\ ${ }^{1}$ Samsung Biomedical Research Institute, Seoul, Republic of Korea \\ ${ }^{2}$ Department of Psychiatry, Samsung Medical Center, Sungkyunkwan University School of Medicine, Seoul, Republic of Korea \\ ${ }^{3}$ Department of Psychiatry, Samsung Medical Center, Seoul, Republic of Korea
}

\begin{abstract}
Objective Panic disorder has been suggested to be divided into the respiratory and non-respiratory subtypes in terms of its clinical presentations. The present study aimed to investigate whether there are any differences in treatment response and clinical characteristics between the respiratory and non-respiratory subtypes of panic disorder patients.
\end{abstract}

Methods Among the 48 patients those who completed the study, 25 panic disorder patients were classified as the respiratory subtype, whereas 23 panic disorder patients were classified as the non-respiratory subtype. All patients were treated with escitalopram or paroxetine for 12 weeks. We measured clinical and psychological characteristics before and after pharmacotherapy using the Panic Disorder Severity Scale (PDSS), Albany Panic and Phobic Questionnaire (APPQ), Anxiety Sensitivity Index-Revised (ASI-R), State-Trait Anxiety Inventory (STAI-T, STAI-S), Hamilton Anxiety Rating Scale (HAM-A), and Hamilton Depression Rating Scale (HAM-D).

Results The prevalence of the agoraphobia was significantly higher in the respiratory group than the non-respiratory group although there were no differences in gender and medication between the two groups. The respiratory group showed higher scores on the fear of respiratory symptoms of the ASI-R. In addition, after pharmacotherapy, the respiratory group showed more improvement in panic symptoms than the non-respiratory group.

Conclusion Panic disorder patients with the respiratory subtype showed more severe clinical presentations, but a greater treatment response to SSRIs than those with non-respiratory subtype. Thus, classification of panic disorder patients as respiratory and non-respiratory subtypes may be useful to predict clinical course and treatment response to SSRIs.

Psychiatry Investig 2014;11(4):412-418

Key Words Panic disorder, Selective Serotonin Reuptake Inhibitors, Clinical subtypes, Treatment outcome.

\section{INTRODUCTION}

According to the Diagnostic and Statistical Manual of Mental Disorders, fourth edition (DSM-IV), panic disorder is considered as a unitary diagnostic category. However, panic disorder shows diverse clinical presentations, prompting some researchers to insist that panic disorder is not a singular illness. ${ }^{1}$ For example, some patients mainly complain of respiratory symptoms such as hyperventilation or shortness of breath, but others mainly present palpitation or dizziness. As the dif-

Received: September 13, 2013 Revised: December 3, 2013

Accepted: December 9, 2013 Available online: October 20, 2014

$\triangle$ Correspondence: Bum-Hee Yu, MD, PhD

Department of Psychiatry, Samsung Medical Center, Sungkyunkwan University School of Medicine, 81 Irwon-ro, Gangnam-gu, Seoul 135-710, Republic of Korea

Tel: +82-2-3410-3583, Fax: +82-2-3410-0050, E-mail: bhyu@skku.edu

(a) This is an Open Access article distributed under the terms of the Creative Commons Attribution Non-Commercial License (http://creativecommons.org/licenses/bync/3.0) which permits unrestricted non-commercial use, distribution, and reproduction in any medium, provided the original work is properly cited. ference in clinical symptoms may be related to the prognosis and disease course of panic disorder, panic disorder can be divided into different clinical subtypes in terms of its clinical presentations and response to treatment. ${ }^{2,3}$

One of the most extensively studied subtypes of panic disorder is the respiratory subtype. Patients who show prominent respiratory symptoms are classified as the respiratory subtype, whereas others who mainly show other physical or cognitive symptoms are designated as the non-respiratory subtype. ${ }^{4-8}$ Panic patients with a respiratory subtype should have four of the five following respiratory symptom criteriafeeling of choking or smothering sensations, shortness of breath, chest pain or discomfort, numbness or tingling sensations, and fear of dying-during a panic attack. Thirty to $65 \%$ of panic disorder patients meet the criteria for the respiratory subtype. ${ }^{1,9,10}$ This distinct subtype is supported by the studies that panic patients with the respiratory subtype are particularly more sensitive to respiratory tests than those with the non-re- 
spiratory subtype. ${ }^{6,11}$

There are several controversial findings regarding the demographic and clinical features associated with the respiratory and non-respiratory subtypes. Some studies showed that panic patients with a respiratory subtype have more severe panic and phobic symptoms while other studies showed contradictory findings. ${ }^{2,5,12}$ Other study showed that patients with a respiratory subtype have more severe anxiety sensitivity compared with those with a non-respiratory subtype. ${ }^{2}$ In addition, a recent study showed that there is a significant difference in the prevalence of agoraphobia between respiratory and non-respiratory subtypes. ${ }^{9}$

In addition to totally different clinical features, the two clinical subtypes also show different epidemiological findings. Panic patients with the respiratory subtype have a higher familial loading of panic disorder, while in the non-respiratory subtypes, depressive episodes are related to an early onset of panic disorder. ${ }^{13}$ In a recent study, the non-respiratory subtype had worse quality of life than the respiratory subtype, although the two subtypes showed similar anxiety and panic symptoms. ${ }^{14}$ In addition, Panic patients with the respiratory subtype also showed a more rapid response to tricyclic antidepressants and less frequent panic attacks, compared with those with the non-respiratory subtype. ${ }^{3}$ However, another study showed that after 3 years of follow-up, there no significant difference was evident in the remission rate between the respiratory and non-respiratory subtypes. ${ }^{13}$

Selective serotonin reuptake inhibitors (SSRIs) are safe and effective anti-panic medications, considering their relatively few adverse effects and better treatment response, compared with tricyclic antidepressants and benzodiazepines. ${ }^{15,16}$ However, no study has examined different treatment efficacies of SSRIs between the two subtypes of panic disorder. As panic disorder seems to be a disease with heterogeneous clinical symptoms, treatment of panic disorder patients according to the clinical subtypes may be important. Thus, the present study aimed to investigate whether there are any differences in treatment response and clinical characteristics between respiratory and non-respiratory subtypes of panic disorder according to SSRI pharmacotherapy.

\section{METHODS}

\section{Subjects}

Participants were men and women over 20 years of age, who met the DSM-IV criteria for panic disorder with or without agoraphobia as determined by the Structured Clinical Interview for DSM-IV. Exclusion criteria were major medical illnesses, comorbid other major psychiatric illnesses, the presence of suicidal risk, pregnancy, and breast-feeding women.
Thus, panic disorder was the primary diagnosis in all cases, but some psychiatric illnesses were comorbid as their secondary diagnoses.

Among the initially recruited 69 panic disorder patients, 21 panic disorder patients dropped out during the study. Among the 48 panic disorder patients who completed the study, 24 were males and 24 were females. Their mean ages were 38.25 (10.05) years and 44.42 (9.91) years, respectively. Nineteen panic disorder patients also had comorbid agoraphobia. There were no significant differences in the demographic data and mean scores of the psychological scales between study completers and dropped out subjects.

Twenty five panic disorder patients who showed at least four or five respiratory symptoms were classified as the respiratory subtype. Twenty three panic disorder patients who showed fewer than four respiratory symptoms were classified as the non-respiratory subtype.

All subjects gave their informed consent to participate in the study after being provided with complete information about the study. This study was approved by the Institutional Review Board of Samsung Medical Center.

\section{Measures}

The Panic Disorder Severity Scale (PDSS) is a 7-item scale to assess multiple dimensions of panic severity. ${ }^{17}$ Each Item is rated on a $0-4$ scale so that total scores range from $0-28$. This scale was used to assess frequency of attacks, degree of distress during attacks, anticipatory anxiety, phobic avoidance of situations, phobic avoidance of sensations, impairment in or interference with work functioning, and impairment in or interference with social functioning. We used the Korean version of the PDSS scale, which has high inter-rater reliability and test-retest reliability. ${ }^{18}$

The Hamilton Depression Rating Scale (HAM-D) is a 17item scale used to assess the severity of depression, ${ }^{19}$ and the Hamilton Anxiety Rating Scale (HAM-A) is a 14-item clinician rating scale to assess the severity of anxiety. ${ }^{20}$ The revised version of Anxiety Sensitivity Index (ASI-R) is a 16-item selfreporting questionnaire ${ }^{21}$ in which respondents indicate on a 5 -point Likert Type scale ( $0=$ very little to $4=$ very much) the extent to which they fear the negative consequences of anxiety symptoms; we used the Korean version of the ASI-R. ${ }^{22}$ The Albany Panic and Phobic Questionnaire (APPQ) is a 27-item instrument designed to measure interoceptive, agoraphobic, and social situational fears, ${ }^{23}$ and we administered the Korean version of the APPQ in the study. ${ }^{24}$ The State-Trait Anxiety Inventory (STAI-T, STAI-S) is each a 20 item instrument designed to measure state and trait anxiety in normal person, and we administered the Korean version of the STAI in the study.

The psychological scales were measured twice at baseline 
and after 12 weeks of treatment.

\section{Drug administration and procedure}

Panic disorder patients were instructed to take a SSRI; paroxetine or escitalopram was used as the drug of choice. Some patients also received a benzodiazepine such as alprazolam during the first month. During the 4 weeks, use of alprazolam was allowed for 12 patients, and their daily doses of alprazolam were $0.40(0.13) \mathrm{mg} /$ day and the daily doses of alprazolam were ranged from $0.25 \mathrm{mg} /$ day to $0.5 \mathrm{mg} /$ day. And use of zolpidem (10 mg/day) was prescribed for only one participant. However, alprazolam and zolpidem were tapered off after 4 weeks, and were discontinued until the 12 week follow up visit. And there was no difference in treatment response between the groups with or without alprazolam use.
Twenty nine panic disorder patients took escitalopram medication; their daily doses of escitalopram were flexibly adjusted from $5 \mathrm{mg} /$ day to $20 \mathrm{mg} /$ day [mean daily dose at the 12 week follow up: 12.93 (6.20) mg/day]. Nineteen panic disorder patients took paroxetine medication and their daily doses of paroxetine were also flexibly adjusted from $10 \mathrm{mg} /$ day to $40 \mathrm{mg} /$ day [mean daily dose at the 12 week follow up: 25.00 (12.83) $\mathrm{mg} /$ day]. The paroxetine equivalent dose of imipramine $150 \mathrm{mg} /$ day was $30 \mathrm{mg} /$ day for panic disorder patients, ${ }^{25}$ and the recommended daily dose of escitalopram for treating panic disorder was 5-20 mg/day. ${ }^{26,27}$ Thus, the mean daily doses of SSRIs in this study seemed to be optimal for treating panic disorder. We defined clinical remission as the absence of full panic attacks and a PDSS score $\leq 7$, in accordance with a previous study. ${ }^{28}$

Table 1. Demographic data and clinical information of study subjects

\begin{tabular}{|c|c|c|c|c|c|}
\hline & \multicolumn{2}{|c|}{ Clinical subtypes } & \multirow{2}{*}{ Total $(\mathrm{N}=48)$} & \multirow{2}{*}{$\chi^{2}$ or $\mathrm{t}$} & \multirow{2}{*}{$\mathrm{p}$} \\
\hline & Respiratory (N=25) & Non-respiratory $(\mathrm{N}=23)$ & & & \\
\hline Gender (\%) & & & & 0.25 & 0.12 \\
\hline Male & $15(60.0)$ & $9(39.1)$ & 24 & & \\
\hline Female & $10(40.0)$ & $14(60.9)$ & 24 & & \\
\hline Agoraphobia (\%) & & & & 5.88 & 0.02 \\
\hline Without & $11(44.0)$ & $18(78.3)$ & 29 & & \\
\hline With & $14(56.0)$ & $5(21.7)$ & 19 & & \\
\hline Education (yr, \%) & & & & 3.48 & 0.48 \\
\hline$\leq 8$ & $0(0.0)$ & $1(4.3)$ & 1 & & \\
\hline 9 & $0(0.0)$ & $1(4.3)$ & 1 & & \\
\hline $10-14$ & $10(40.0)$ & $8(34.8)$ & 18 & & \\
\hline 16 & $15(60.0)$ & $12(52.2)$ & 27 & & \\
\hline$\geq 16$ & $0(0.0)$ & $1(4.3)$ & 1 & & \\
\hline Number of SSRI users (N) & & & & 4.38 & 0.22 \\
\hline Escitalopram & 16 & 13 & 29 & & \\
\hline Paroxetine & 9 & 10 & 19 & & \\
\hline \multicolumn{6}{|l|}{ Comorbidity } \\
\hline GAD & 1 & 1 & & & \\
\hline SAD & 2 & 0 & & & \\
\hline MDD & 0 & 1 & & & \\
\hline Dysthymic & 1 & 0 & & & \\
\hline \multicolumn{6}{|c|}{ Mean dosage of medications (mg)* } \\
\hline Escitalopram & $14.06(4.55)$ & $11.54(7.74)$ & $12.93(6.20)$ & 1.09 & 0.28 \\
\hline Paroxetine & $23.61(14.58)$ & $26.25(11.68)$ & $25.00(12.83)$ & -0.44 & 0.67 \\
\hline Age (mean of yr) & $38.20(10.80)$ & $44.74(8.86)$ & & -2.28 & 0.03 \\
\hline Age of onset (mean of yr) & $35.44(10.54)$ & $41.52(9.11)$ & & -2.13 & 0.04 \\
\hline Duration of illness (yr) & $2.76(6.06)$ & $3.22(3.93)$ & & -0.31 & 0.76 \\
\hline Number of PD symptoms & $7.52(1.71)$ & $5.52(1.38)$ & & 4.43 & 0.00 \\
\hline
\end{tabular}

Statistics were analyzed by chi-square test and t-test. *mean dosage of medications at the final follow up. GAD: generalized anxiety disorder, SAD: social anxiety disorder, MDD: major depressive disorder, Dysthymic: dysthymic disorder 
Table 2. Descriptive information about the panic symptoms according to the clinical subtypes of panic disorder

\begin{tabular}{lcccc}
\hline \multicolumn{1}{c}{ Panic symptoms } & Respiratory $(\mathrm{N}=25)$ & Non-respiratory $(\mathrm{N}=23)$ & Total $(\mathrm{N}=48)$ & $\mathrm{p}$ \\
\hline Palpitation (\%) & $21(84.0)$ & $19(82.6)$ & $40(83.3)$ & $18(37.5)$ \\
Sweating (\%) & $10(40.0)$ & $8(34.8)$ & $13(27.1)$ & 0.77 \\
Trembling/shaking (\%) & $7(28.0)$ & $6(26.1)$ & $39(81.3)$ & 1.00 \\
Shortness of breath/smothering (\%) & $25(100.0)$ & $14(60.9)$ & $25(52.1)$ & 0.00 \\
Feeling of choking (\%) & $21(84.0)$ & $4(17.4)$ & $36(75.0)$ & 0.00 \\
Chest pain (\%) & $24(96.0)$ & $12(52.2)$ & $13(27.1)$ & 0.00 \\
Nausea (\%) & $7(28.0)$ & $6(26.1)$ & $37(77.1)$ & $3(6.3)$ \\
Unsteady/lightheaded/faint (\%) & $18(72.0)$ & $19(82.6)$ & $19(39.6)$ & 0.50 \\
Derealization/depersonalization (\%) & $2(8.0)$ & $10(43.5)$ & $39(81.3)$ & 0.00 \\
Fear of 'going crazy' (\%) & $9(36.0)$ & $14(60.9)$ & $16(33.3)$ & 0.00 \\
Fear of dying (\%) & $25(100)$ & $5(21.7)$ & $17(35.4)$ & 0.13 \\
Paresthesias/tingling (\%) & $11(44)$ & $9(39.1)$ & 0.76 \\
Chills/hot flushes (\%) & $8(32.0)$ & &
\end{tabular}

\section{Statistical analyses}

To control missing values for a given evaluation, we used the last-observation-carried forward (LOCF) method. The statistical Package for Social Science (SPSS) for Windows (version 19) was used for all statistical analysis. Statistical significance was defined at the 0.05 level. Chi-square tests were conducted to examine possible differences in the categorical variables. After normality of the data was confirmed by the Shapiro-Wilk test, the $t$ test was used for independent groups to evaluate differences in the continuous variables. If the data were not normally distributed, the Mann-Whitney U test was used. And ANOVA test was used to clarify whether certain factors have an effect on the outcome after removing the confounding variable's effect (covariates).

\section{RESULTS}

Demographic variables of the respiratory and non-respiratory groups are described in Table 1 . There were no significant differences in gender, education, duration of illness between the respiratory subtype and the non-respiratory subtype. However, the mean age $(t=-2.28, p=0.03)$ and age of onset $(t=-2.13$, $\mathrm{p}=0.04$ ) was significantly lower in the respiratory group than in the non-respiratory group.

There were no differences in the demographic data and clinical features between the escitalopram group and the paroxetine group. In addition, we also compared the treatment effect between the SSRI alone and SSRI plus BDZ groups, and there were no differences in the dropout rate $\left(X^{2}=0.51, p=0.33\right)$ and PDSS scores between the two groups $(\mathrm{t}=1.53, \mathrm{p}=0.13)$.

The respiratory group had an average of 7.52 (1.71) symptoms of the 13 panic symptoms, whereas the non-respiratory group had an average of 5.52 (1.38) of the total symptoms.
Thus, the respiratory group showed more panic symptoms than the non-respiratory group at the baseline $(\mathrm{t}=4.43, \mathrm{p}=0.00)$.

Table 2 compares the frequency of panic symptoms between the respiratory and non-respiratory subtypes. The most frequently reported symptom in both subtypes was 'palpitation' followed by 'fear of dying' and 'shortness of breath'.

Table 3 shows age-adjusted clinical and psychological characteristics of the two PD groups. The respiratory group showed higher scores on the fear of respiratory symptoms of the ASI-R. As presented in Table 4, we compared the mean changes after 12 weeks of treatment. The respiratory group showed more improvement in panic severity than the non-respiratory group $(\mathrm{t}=-2.13, \mathrm{p}=0.04)$.

\section{DISCUSSION}

In this study, the respiratory subtype seems to be different from non-respiratory subtype in terms of some clinical characteristics of panic disorder. The respiratory subtype group showed younger age and age of disease onset than the nonrespiratory subtype group. This finding suggests that the respiratory subtype may develop earlier than non-respiratory subtype in panic disorder patients. In addition, the respiratory subtype was more frequently comorbid with agoraphobia than the non-respiratory subtype. This finding is consistent with earlier results showing that agoraphobic fear may be more related to the respiratory subtype than the non-respiratory subtype. ${ }^{3,9,13}$ In a recent study, agoraphobic fear was suggested to affect panic symptom severity and time to remission. ${ }^{29}$ Thus, patients with the respiratory subtype might show severe panic symptoms because of comorbidity with agoraphobia.

We found that the respiratory subtype showed higher 
Table 3. Comparisions of age-adjusted means of clinical and psychological variables between the respiratory and the nonrespiratory subtypes at baseline

\begin{tabular}{|c|c|c|c|c|}
\hline & \multicolumn{2}{|c|}{ Subtypes } & \multirow[b]{2}{*}{$\mathrm{F}$} & \multirow[b]{2}{*}{$\mathrm{p}$} \\
\hline & $\begin{array}{l}\text { Respiratory } \\
\quad(\mathrm{N}=25)\end{array}$ & $\begin{array}{l}\text { Non-respiratory } \\
\quad(\mathrm{N}=23)\end{array}$ & & \\
\hline Age (Ref) & $38.20(10.80)$ & $44.74(8.86)$ & -2.28 & 0.03 \\
\hline PDSS & $12.76(3.74)$ & $11.30(4.09)$ & 0.50 & 0.48 \\
\hline HAM-A & $16.04(6.41)$ & $14.57(7.06)$ & 0.01 & 0.91 \\
\hline HAM-D & $12.80(4.06)$ & $11.43(4.25)$ & 0.16 & 0.69 \\
\hline ASI-R car & $19.04(9.87)$ & $14.04(8.95)$ & 0.20 & 0.15 \\
\hline ASI-R pub & $11.40(7.09)$ & $9.61(6.84)$ & 0.01 & 0.92 \\
\hline ASI-R res & $25.80(10.86)$ & $18.35(9.23)$ & 4.53 & 0.04 \\
\hline ASI-R cog & $7.52(6.52)$ & $6.13(5.90)$ & 0.01 & 0.94 \\
\hline ASI-R & $63.76(28.03)$ & $48.13(22.80)$ & 2.15 & 0.15 \\
\hline APPQ agora & $19.92(14.07)$ & $18.70(13.60)$ & 0.02 & 0.89 \\
\hline APPQ soc & $22.00(16.10)$ & $16.74(15.96)$ & 0.34 & 0.57 \\
\hline APPQ inte & $20.52(16.66)$ & $14.83(12.72)$ & 1.25 & 0.27 \\
\hline APPQ & $61.24(38.59)$ & $50.26(33.73)$ & 0.43 & 0.52 \\
\hline STAI-S & $50.04(9.93)$ & $45.22(12.00)$ & 1.32 & 0.26 \\
\hline STAI-T & $48.96(10.06)$ & $44.61(9.41)$ & 0.89 & 0.35 \\
\hline
\end{tabular}

PDSS: Panic disorder severity scale, HAM-A: The Hamilton Anxiety Rating Scale, HAM-D: The Hamilton Depression Rating Scale, ASIR: Anxiety Sensitivity Index-revised, ASI-R car: fear of cardiovascular symptoms, ASI-R pub: fear of publicly observable anxiety reactions, ASI-R res: fear of respiratory symptoms, ASI-R cog: fear of cognitive dyscontrol, APPQ: Albany Panic and Phobic Questionnaire, APPQ agora: agoraphobic fear, APPQ soc: social situations, APPQ inte: interoceptive fear, STAI-S: Spielberger State Anxiety Inventory, STAI-T: Spielberger Trait Anxiety Inventory

scores on the fear of respiratory symptoms of the ASI-R than the non-respiratory subtype. The respiratory group showed a higher attention to physical sensations or feeling than the non-respiratory subtype. It seems that the respiratory subtype is the possibility of increased physiological hyper-arousal at the internal and external stimulus. In addition, we found that the respiratory group showed more panic symptoms, compared with the non-respiratory group. The respiratory group might have higher panic severity, although the PDSS scores were not statistically different between the two subtypes in this study.

A recent study showed that distress during panic attacks, anticipatory anxiety, agoraphobic fear and impairment in work functioning in the respiratory subtype were higher than the non-respiratory subtype since the respiratory subtype may have more catastrophic cognitions about their symptoms than the non-respiratory subtype. ${ }^{9}$ In this study, almost all the respiratory group showed fear of dying, shortness of breath, and chest pain that are closely related to catastrophic cognitions. Catastrophic cognitions that occur during a panic attack
Table 4. Comparisons of clinical and psychological changes after pharmacotherapy between the respiratory and the non-respiratory subtypes

\begin{tabular}{lcccc}
\hline & \multicolumn{2}{c}{ Clinical subtypes } & \\
\cline { 2 - 3 } & $\begin{array}{c}\text { Respiratory } \\
(\mathrm{N}=25)\end{array}$ & $\begin{array}{c}\text { Non-respiratory } \\
(\mathrm{N}=23)\end{array}$ & $\mathrm{p}$ \\
\hline PDSS & $-9.48(4.04)$ & $-6.96(4.15)$ & 0.04 \\
HAM-A & $-9.72(6.01)$ & $-6.74(6.08)$ & 0.09 \\
HAM-D & $-8.22(3.97)$ & $-6.55(3.50)$ & 0.15 \\
ASI-R & $-30.70(30.27)$ & $-30.45(24.35)$ & 0.98 \\
APPQ & $-17.83(39.74)$ & $-23.60(31.88)$ & 0.61 \\
STAI-S & $-12.65(13.42)$ & $-12.83(17.48)$ & 0.97 \\
STAI-T & $-12.04(12.45)$ & $-13.91(20.29)$ & 0.70 \\
\hline & Respiratory & Non-respiratory & $\chi^{2}$ & $\mathrm{p}$ \\
\hline Remission & & & & \\
Y (\%) & $21(84.0)$ & $19(82.6)$ & 0.90 & 1.00 \\
N (\%) & $4(16.0)$ & $4(17.4)$ & \\
\hline PDSS: Panc dic & & & \\
\hline
\end{tabular}

PDSS: Panic disorder severity scale, HAM-A: The Hamilton Anxiety Rating Scale, HAM-D: The Hamilton Depression Rating Scale, ASI-R: Anxiety Sensitivity Index-revised, APPQ: Albany Panic and Phobic Questionnaire, STAI-S: Spielberger State Anxiety Inventory, STAI-T: Spielberger Trait Anxiety Inventory

are known to strongly affect a fear of anxiety sensations, and one of the most observable panic symptoms, 'fear of dying', is most related to anxiety sensitivity. ${ }^{30} \mathrm{~A}$ previous study showed that changes of anxiety sensitivity may be an important factor predicting treatment response in panic disorder. ${ }^{31}$ Howev$\mathrm{er}$, in this study, there were no differences in reduction of anxiety sensitivity between the two subtypes. Thus, relationships between anxiety sensitivity and respiratory subtype need to be examined further.

The close relationships between serotonin and panic disorder have been suggested, and tryptophan depletion is known to increase rate of panic attacks and anxiety responses in panic disorder. According to a meta-analysis which compared the short-term efficacy and side-effects of antidepressants for the treatment of panic disorder, SSRIs (citalopram, paroxetine, sertraline etc.) showed higher anti-panic efficacy than other medications. ${ }^{32}$

In this study, the respiratory group showed a greater reduction in panic-specific symptoms (reflected by the PDSS scores) than the non-respiratory group, although there were no differences in improvement of general anxiety and depressive symptoms. Thus, SSRIs might be more effective for the treatment of panic-specific symptoms in the respiratory subtype. Several studies indicate that anxious patients exhibit irregular breathing patterns as measured by tidal volume and respiratory rate. ${ }^{33}$ In addition, considering the possible direct effect of paroxetine on respiration in animal experimentations, SSRIs may directly affect the respiratory modulation in panic 
disorder patients. ${ }^{34}$ The effective therapeutic responses of benzodiazepine and tricyclic antidepressant according to the clinical subtypes of panic disorder have been reported in the earlier studies, ${ }^{3,13}$ but there has been no study to examine treatment efficacies of SSRIs according to the clinical subtypes of panic disorder.

SSRIs are generally better tolerated than tricyclic antidepressant. According to a previous study, TCA-treated patients showed a significantly higher dropout rate (31\%), compared with the SSRI- treated patients (18\%) although TCA and SSRIs had equal efficacy for the treatment of panic disorder. ${ }^{35} \mathrm{In}$ another study, more adverse effects were reported in the clomipramine group compared with the paroxetine group. ${ }^{36}$

Nardi et al. ${ }^{37}$ also showed that benzodiazepines and SSRIs have different adverse effect profiles, which may affect a dropout rate of panic disorder patients. Katzelnick et al. ${ }^{15}$ reported that combination of SSRI and benzodiazepines was more effective than SSRI alone in the panic disorder, but our study did not found any difference in treatment efficacy between them.

Our study has some major limitations. Firstly, we did not consider other important clinical variables such as mean age, duration of illness and other comorbid psychiatric disorders, which might lead to some bias in interpreting the study results. In some studies, respiratory panic reported greater familial history of any mental illness, such as major depressive disorder, other anxiety disorder. Panic disorder which is comorbid with other anxiety and/or affective disorders show more severe anxiety symptoms than patients without comorbid other psychiatric disorders. ${ }^{38}$ Recently, Robertson-Nay et al. ${ }^{7}$ suggested that the respiratory subtype is associated with higher comorbidity with agoraphobia, generalized anxiety disorder, social phobia, specific phobia, and major depressive disorder. However, in this study, we did not find higher comorbidity with psychiatric illnesses in the respiratory subtype. Secondly, a relatively high proportion of the panic disorder patients dropped out during the study. However, those who dropped out were not different from those who completed the study in terms of baseline disease severity and psychological characteristics. Thirdly, this study included too small sample size of subjects to extend to a general panic disorder population, and thus, we could not analyze the effects of other important variables such as age, gender, medications, and presence of agoraphobia in this study. This study should be considered as an exploratory study. To examine the exact psychopathology of the panic disorder subtype would require a lager patient sample size, with the other possible subtype. Finally, this study was too short to predict clinical course and treatment response. As mean remission time of panic disorder has been reported as 5.7 months and $43.3 \%$ of the PD patients still can display panic symptoms after 1 year of phar- macotherapy, ${ }^{39}$ a longer prospective study with a larger sample size will be necessary in the future.

In conclusion, panic disorder patients with the respiratory subtype showed more severe clinical presentations, but a greater treatment response to SSRIs, than those with non-respiratory subtype. Thus, classification of panic disorder patients as respiratory and non-respiratory subtypes may be useful to predict clinical course and treatment response to SSRIs.

\section{Acknowledgments}

This study was supported by the Samsung Biomedical Research Institute (SBRI) grants CA6-218, CA9-222, and CRO 112122.

\section{REFERENCES}

1. Kircanski K, Craske MG, Epstein AM, Wittchen HU. Subtypes of panic attacks: a critical review of the empirical literature. Depress Anxiety 2009;26:878-887.

2. Onur E, Alkin T, Tural U. Panic disorder subtypes: further clinical differences. Depress Anxiety 2007;24:479-486.

3. Valcnca AM, Nardi AE, Mezzasalma MA, Nascimento I, Zin WA, Lopes FL, et al. Therapeutic response to benzodiazepine in panic disorder subtypes. Sao Paulo Med J 2003;121:77-80.

4. Klein DF. False suffocation alarms, spontaneous panics, and related conditions. An integrative hypothesis. Arch Gen Psychiatry 1993;50:306317.

5. Briggs AC, Stretch DD, Brandon S. Subtyping of panic disorder by symptom profile. Br J Psychiatry 1993;163:201-209.

6. Freire RC, Lopes FL, Valença AM, Nascimento I, Veras AB, Mezzasalma $\mathrm{MA}$, et al. Panic disorder respiratory subtype: a comparison between responses to hyperventilation and $\mathrm{CO} 2$ challenge tests. Psychiatry Res 2008;157:307-310.

7. Roberson-Nay R, Kendler KS. Panic disorder and its subtypes: a comprehensive analysis of panic symptom heterogeneity using epidemiological and treatment seeking samples. Psychol Med 2011;41:2411-2421.

8. Sarp A, Arik AC, Guz H, Sahin AR, Abanoz Z. Possible subtypes of panic disorder. Turk Psikiyatri Derg 2010;21:269-279.

9. Ha JW, Lim SW, Oh KS. Comparison of clinical characteristics between respiratory and non-respiratory subtypes of panic disorder. Korean J Biol Psychiatry 2009;16:46-52.

10. Freire RC, Valença AM, Nascimento I, Lopes FL, Mezzasalma MA, Zin WA, et al. Clinical features of respiratory and nocturnal panic disorder subtypes. Psychiatry Res 2007;152:287-291.

11. Nardi AE, Freire RC, Zin WA. Panic disorder and control of breathing. Respir Physiol Neurobiol 2009;167:133-143.

12. Biber B, Alkin T. Panic disorder subtypes: differential responses to $\mathrm{CO} 2$ challenge. Am J Psychiatry 1999;156:739-744.

13. Nardi AE, Valença AM, Nascimento I, Lopes FL, Mezzasalma MA, Freire RC, et al. A three-year follow-up study of patients with the respiratory subtype of panic disorder after treatment with clonazepam. Psychiatry Res 2005; 137:61-70.

14. de-Melo-Neto VL, King AL, Valenca AM, da Rocha Freire RC, Nardi AE. Respiratory and non-respiratory panic disorder subtypes: clinical and quality of life comparisons. Rev Port Pneumol 2009;15:859-874.

15. Katzelnick DJ, Saidi J, Vanelli MR, Jefferson JW, Harper JM, McCrary KE. Time to response in panic disorder in a naturalistic setting: combination therapy with alprazolam orally disintegrating tablets and serotonin reuptake inhibitors compared to serotonin reuptake inhibitors alone. Psychiatry (Edgmont) 2006;3:39-49.

16. Freire RC, Hallak JE, Crippa JA, Nardi AE. New treatment options for panic disorder: clinical trials from 2000 to 2010. Expert Opin Pharmacother 2011;12:1419-1428. 
17. Shear MK, Brown TA, Barlow DH, Money R, Sholomskas DE, Woods SW, et al. Multicenter collaborative panic disorder severity scale. Am J Psychiatry 1997;154:1571-1575.

18. JB K. Development of the Korean version of the panic disorder severity scale. Korean J Psychopathol 2001;10:140-151.

19. Hamilton M. A rating scale for depression. J Neurol Neurosurg Psychiatry 1960;23:56-62.

20. Hamilton M. The assessment of anxiety states by rating. Br J Med Psychol 1959;32:50-55.

21. Taylor S, Cox BJ. An expanded anxiety sensitivity index: evidence for a hierarchic structure in a clinical sample. J Anxiety Disord 1998;12:463483.

22. Kim JH, Yu BH, Oh KS, Yang JC, Kim Y, Lee SY, et al. A validation study of Korean Anxiety Sensitivity Index-Revised (ASI-R). J Korean Neuropsychiatr Assoc 2004;43:54-61.

23. Rapee RM, Craske MG, Barlow DH. Assessment instrument for panic disorder that includes fear of sensation-producing activities: the Albany Panic and Phobia Questionnaire. Anxiety 1994-1995;1:114-122.

24. Kim JH, Yang JC, Kim JB, Lim KY, Lee SY, Yu BH. A validation study of Korean Albany Panic and Phobia Questionnaire (APPQ). J Korean Neuropsychiatr Assoc 2004;43:329-336.

25. Bollini P, Pampallona S, Tibaldi G, Kupelnick B, Munizza C. Effectiveness of antidepressants. Meta-analysis of dose-effect relationships in randomised clinical trials. Br J Psychiatry 1999;174:297-303.

26. Nutt DJ. Overview of diagnosis and drug treatments of anxiety disorders. CNS Spectr 2005;10:49-56.

27. Bandelow B, Sher L, Bunevicius R, Hollander E, Kasper S, Zohar J, et al. Guidelines for the pharmacological treatment of anxiety disorders, obsessive-compulsive disorder and posttraumatic stress disorder in primary care. Int J Psychiatry Clin Pract 2012;16:77-84.

28. Furukawa TA, Katherine Shear M, Barlow DH, Gorman JM, Woods SW, Money R, et al. Evidence-based guidelines for interpretation of the Panic Disorder Severity Scale. Depress Anxiety 2009;26:922-929.

29. Park HJ, Kim EJ, Ku JI, Woo JM, Lee SH, Chung SK, et al. Psychological characteristics of early remitters in patients with panic disorder. Psychiatry Res 2012;197:237-241.

30. Cox BJ, Endler NS, Swinson RP. Anxiety sensitivity and panic attack symptomatology. Behav Res Ther 1995;33:833-836.

31. Simon NM, Otto MW, Smits JA, Nicolaou DC, Reese HE, Pollack MH. Changes in anxiety sensitivity with pharmacotherapy for panic disorder. J Psychiatr Res 2004;38:491-495.

32. Andrisano C, Chiesa A, Serretti A. Newer antidepressants and panic disorder: a meta-analysis. Int Clin Psychopharmacol 2013;28:33-45.

33. Yeragani VK, Rao R, Tancer M, Uhde T. Paroxetine decreases respiratory irregularity of linear and nonlinear measures of respiration in patients with panic disorder. A preliminary report. Neuropsychobiology 2004; 49:53-57.

34. Olsson M, Annerbrink K, Bengtsson F, Hedner J, Eriksson E. Paroxetine influences respiration in rats: implications for the treatment of panic disorder. Eur Neuropsychopharmacol 2004;14:29-37.

35. Bakker A, van Balkom AJ, Spinhoven P. SSRIs vs. TCAs in the treatment of panic disorder: a meta-analysis. Acta Psychiatr Scand 2002;106:163167.

36. Lecrubier Y, Bakker A, Dunbar G, Judge R. A comparison of paroxetine, clomipramine and placebo in the treatment of panic disorder. Collaborative Paroxetine Panic Study Investigators. Acta Psychiatr Scand 1997; 95:145-152.

37. Nardi AE, Freire RC, Mochcovitch MD, Amrein R, Levitan MN, King $\mathrm{AL}$, et al. A randomized, naturalistic, parallel-group study for the longterm treatment of panic disorder with clonazepam or paroxetine. J Clin Psychopharmacol 2012;32:120-126.

38. Miyazaki M, Yoshino A, Nomura S. Relationships between anxiety severity, diagnosis of multiple anxiety disorders, and comorbid major depressive disorder. Asian J Psychiatr 2011;4:293-296.

39. Batelaan NM, de Graaf R, Spijker J, Smit JH, van Balkom AJ, Vollebergh WA, et al. The course of panic attacks in individuals with panic disorder and subthreshold panic disorder: a population-based study. J Affect Disord 2010;121:30-38. 